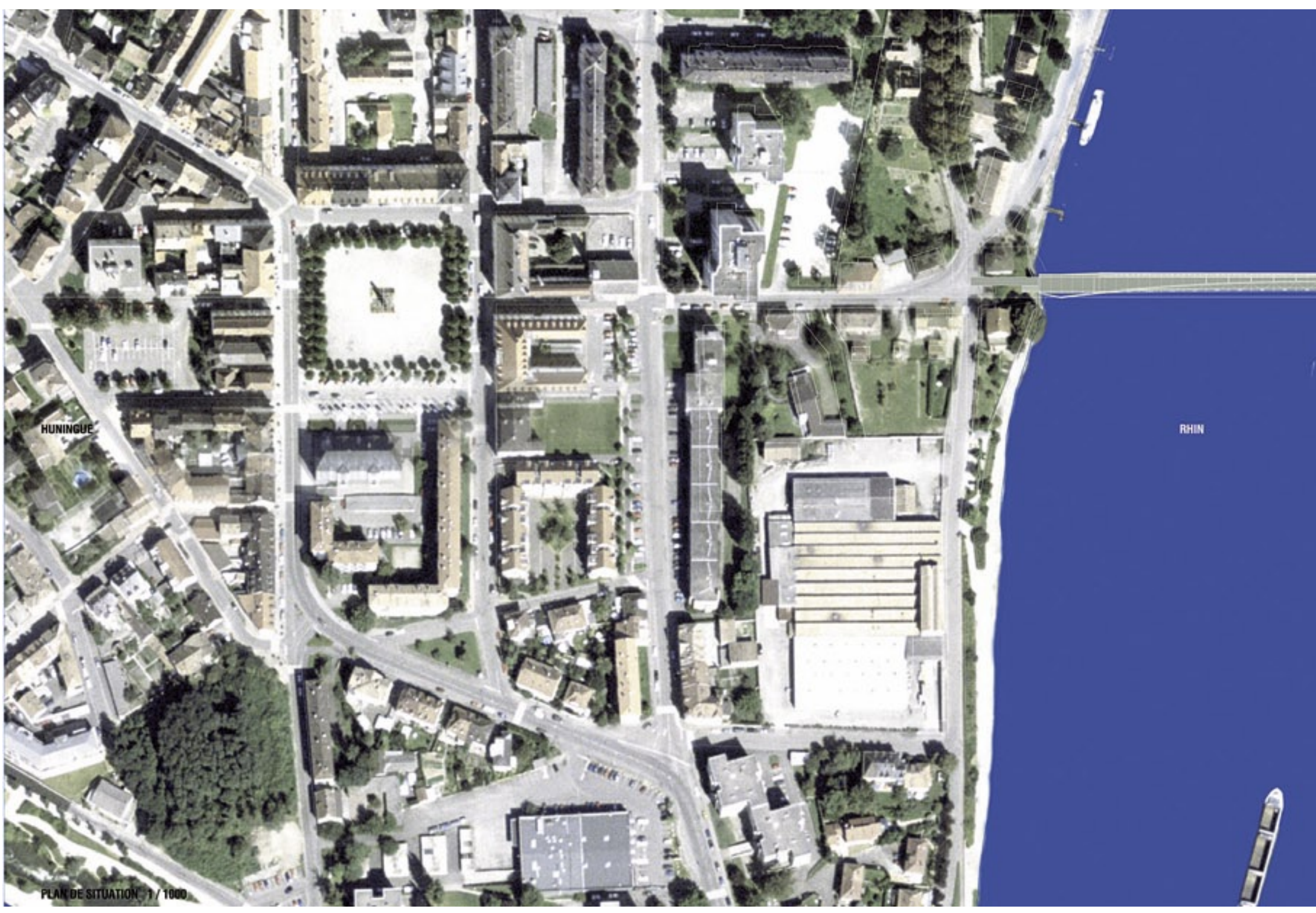

Fotomontaje del emplazamiento. A la derecha, la orilla alemana, a la izquierda el lado francés

Entendemos el trabajo del arquitecto como algo que opone cierta resistencia a la naturaleza: cubre del sol y la lluvia, divide del descampado, o salva un obstáculo. Este puente peatonal se levanta sobre el Rbin (proyectado por un arquitecto de nuestra escuela), donde se encuentran Alemania, Francia y Suiza, en un contexto de flujos e intercambios de gran densidad. Esa densidad habla de cierta escala y de una manera de moverse que no convierte la frontera en un momento notable: apenas un episodio en el trayecto de la casa al mercado. Palabras clave: Francia, concursos, puentes, pasarela peatona.

We conceive of the architect's project as something that opposes a kind of resistance to nature: it shelters from the sun and the rain, it separates us from the open air, or it helps us to overcom geographical difficulties. This pedestrians bridge, projected $b y$ an architect formed in our school, stands over the Rhin, where Germany, France and Switzerland meet, in a context of very dense flux and exchange. This density is related to a certain scale and a way of moving that does not emphasize the border a significant moment: it is scarcely a moment on the way from the house to the marketplace.
Un puente puede alcanzar un valor simbólico que va más allá de su función como conector al convertirse en punto de referencia en una ciudad y en el paisaje. Es el caso de la situación geográfica de esta pasarela, sobre el ancho lecho del Rhin, y de su situación política como puerta de entrada a las tres fronteras de Francia, Alemania y Suiza. $\mathrm{El}$ encargo del concurso ${ }^{1}$ convocado por ambos municipios, francés y alemán, busca darle al puente esa connotación.

El eje visual entre la calle principal de Weil am Rhein, la Hauptstraße, y de la Rue de France del lado francés culmina en la torre central de la plaza cuadrada de Huningue. La pasarela permite completar la conexión física desplazándose lateralmente de este eje para no obturar su percepción. Su forma y estructura son consecuencia de este emplazamiento.

El arco rebajado propuesto aparece como un movimiento claro sobre el río y el paisaje, adquiriendo la fuerza expresiva y estructural de un bow-string. Su situación y altura privilegiada sobre el agua lo convierten en un alto mirador en el valle.

Los elementos portantes son dos arcos: uno vertical, formado por dos tubos hexagonales, y otro inclinado formado por un único tubo que se apoya en el primer arco. La sección asimétrica se 


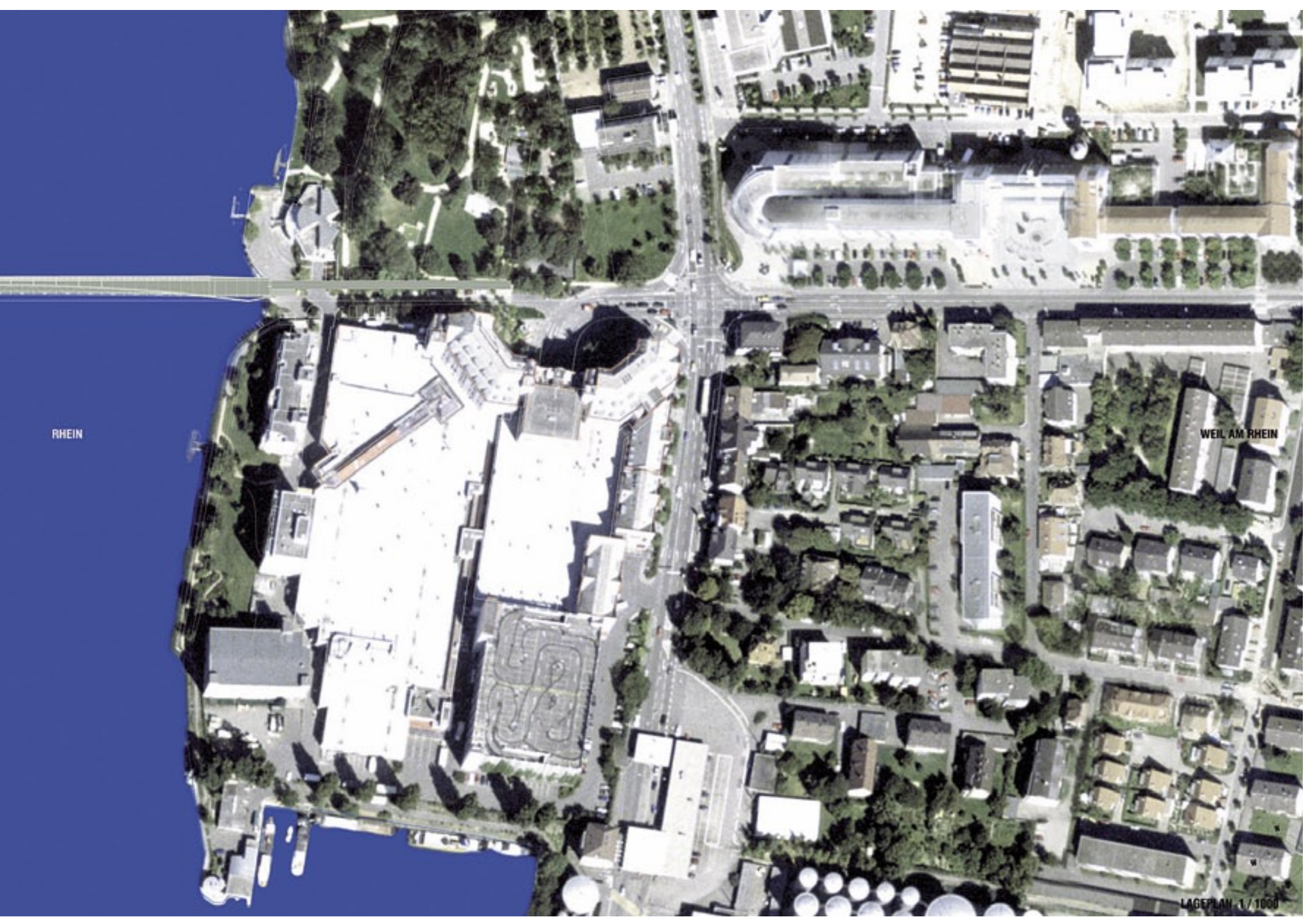

\section{Pasarela para peatones y ciclistas}

abre hacia el eje visual, ampliando su alcance. Los apoyos del puente se sitúan cerca de las orillas del río liberando la parte central a la navegación. En el lado francés el apoyo es fijo mientras que en el lado alemán es móvil al quedar protegido de choques por el avance de la ribera.

El puente cobra un mayor ancho al llegar a las orillas permitiendo la ubicación de rampas y escaleras en línea. Su pendiente y largo se adaptan a las condiciones topográficas de ambos lados. En Weil am Rhein una rampa de $4 \%$ une el puente directamente al parque, mientras que una escalera permite el acceso directo desde la orilla. En
Huningue la rampa se confunde con la topografía de la fortificación Vauban del siglo XVIII.

La estructura del piso es también asimétrica, con una viga longitudinal principal en el lado norte que sostiene los largueros cada cinco metros. Estos travesaños se apoyan en el lado sur a un tubo de sección más reducida. El suelo es una placa nervada de acero que sirve de diafragma en el sentido transversal, transmitiendo los esfuerzos horizontales; el pavimento es en resina epoxy adherente a la placa de acero con un tratamiento antideslizante.

La balaustrada es una malla de acero inoxidable tensada, que mantiene la transparencia hacia el río creando una suerte de halo sobre el puente. Un perfil en aluminio extruido constituye el pasamanos que integra a su vez la iluminación, marcando la línea de unión entre los dos lados. Este sistema de iluminación se completa con pequeños reflectores en los cables que iluminan la parte baja del arco, dibujando su silueta en la noche. ARQ

\begin{tabular}{ll}
\hline 1 Jurado el 19 de octubre de 2001 & 4. Marc Mimram, Paris, Francia. \\
Los equipos concursantes: & 5. Alain Spielmann, Paris, Francia. \\
1. Schlaich, Bergermann und & 6. APAAR (Sarl Doyelle), Plaine, \\
Partner GbR, Stuttgart con Moser & Francia. \\
Architekten, Lorrach, Alemania. & 7. Feichtinger Architectes, Paris, \\
2. Prof. Eibl und Parther GbR, & Francia con Leonhardt, Andrä und \\
Karlsruhe, Alemania. & Partner, Stuttgart, Alemania. \\
3. Regio Ingenieure Oehler con & \\
Prof. René Walther, Lörrach, & \\
Alemania. &
\end{tabular}



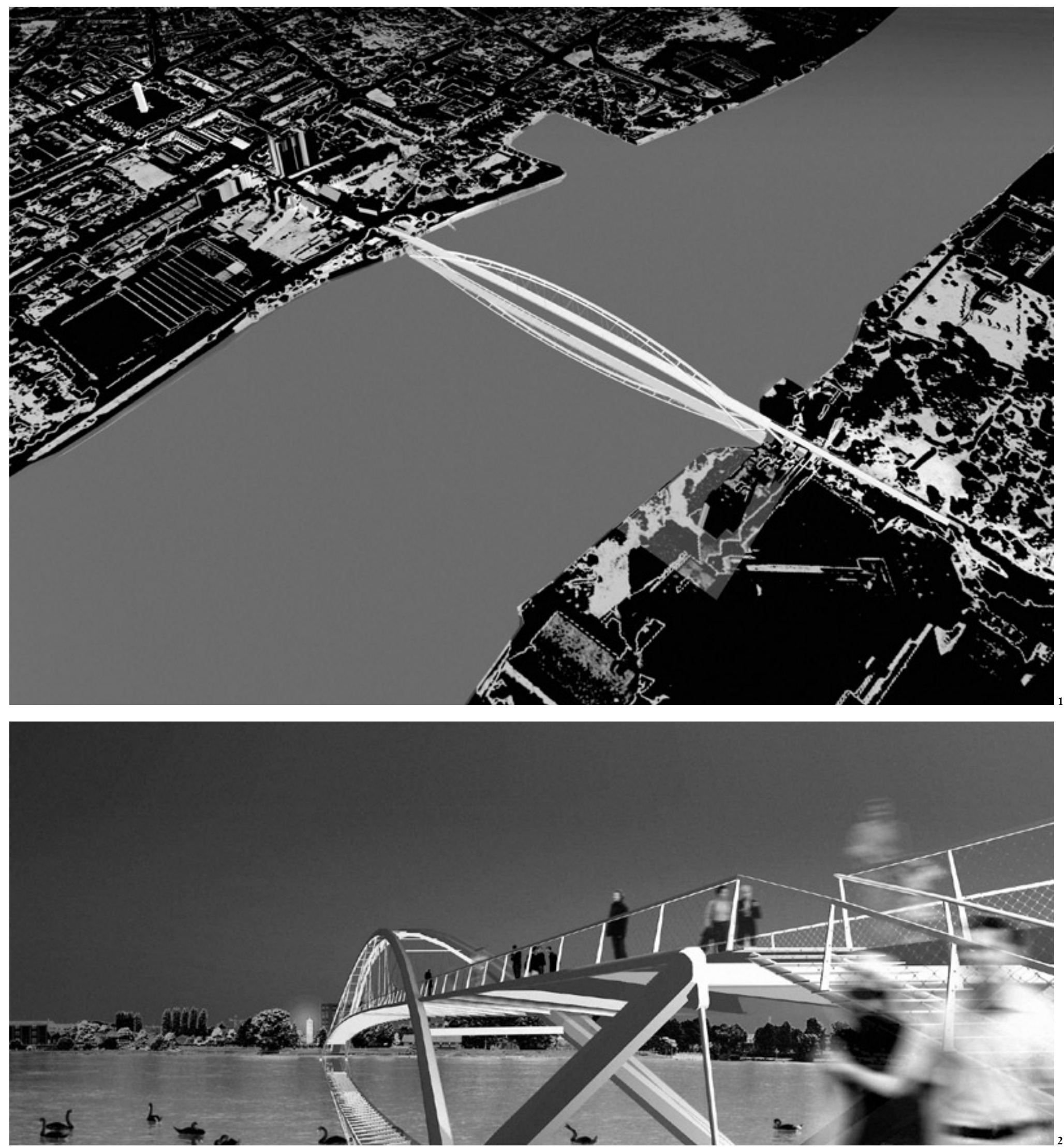

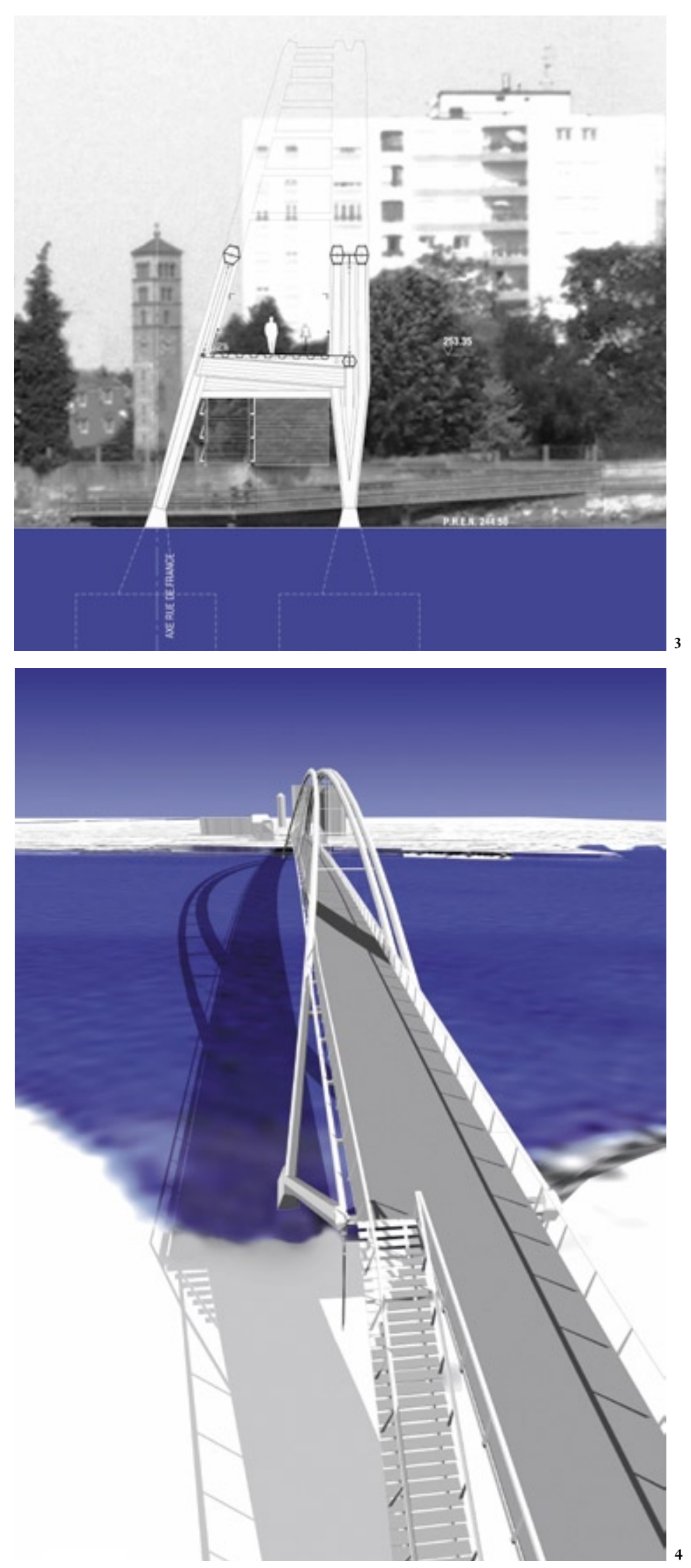

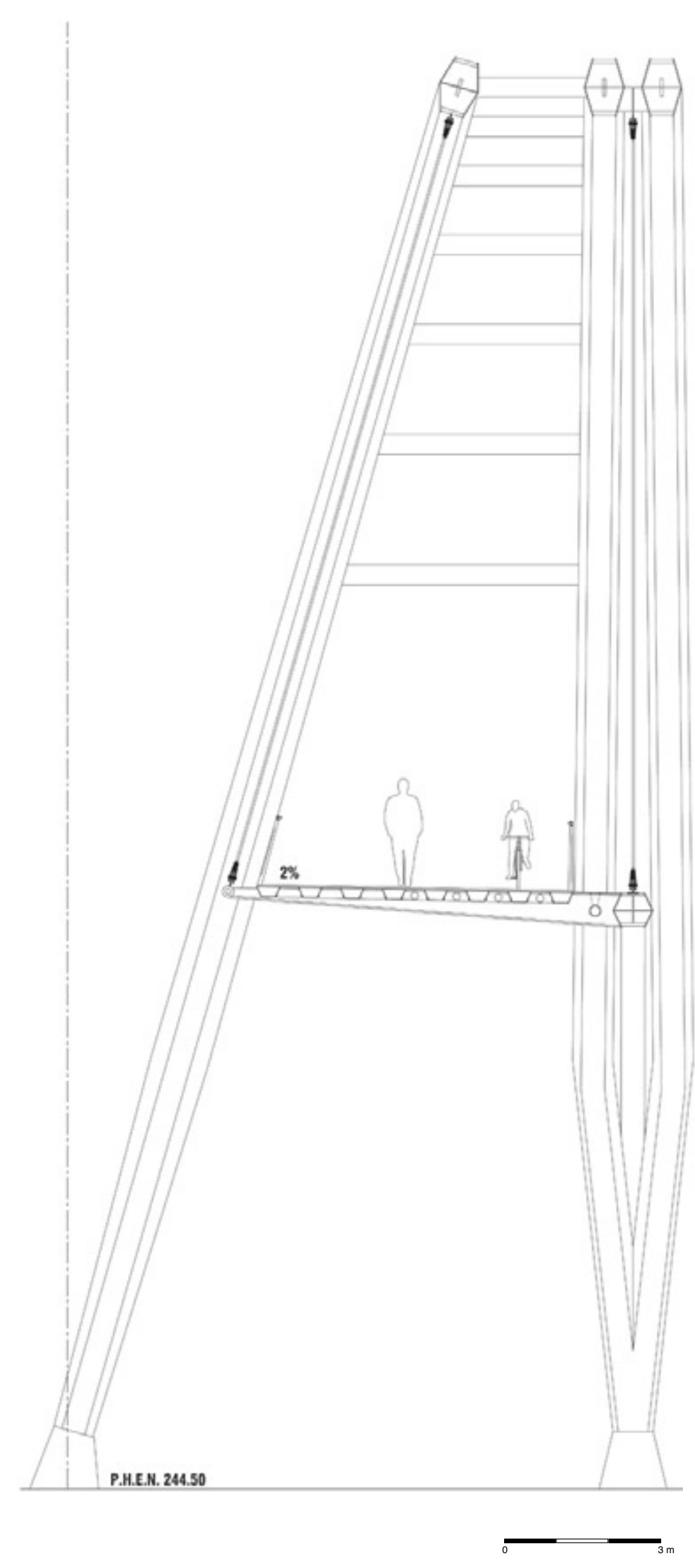

Pasarela para peatones y ciclistas sobre el Rhin

Arquitectos Feichtinger Architectes

Arquitectos colaboradores José Luis Fuentes (jefe de proyecto),

Wolfgang Juen, Paul-Eric Schirr-Bonnans, Ulrike Plos,

Mendis Thilan, Frederique Bindji

Ubicación Weil am Rhein, Alemania, y Huningue, Francia

Mandante Municipio de Huningue y Municipio de Weil am Rhein

Cálculo Leonhardt, Andrä und Partner GmbH.

Materialidad acero, aluminio, pavimento epoxy

Largo total $250 \mathrm{~m}$

Luz $230 \mathrm{~m}$

Año proyecto 2001, construcción 2003-2004

Imágenes Feichtinger Architectes 